\title{
Characteristics of people who died by suicide: record review of two and half years from the National Referral Hospital, Bhutan
}

\author{
Norbu $^{1}$, Chencho Dorji ${ }^{2}$, Kuenzang Norbu ${ }^{3}$, Kencho Peldon ${ }^{4}$ \\ ${ }^{1-4}$ Department of Forensic Medicine, Jigme Dorji Wangchuck National Referral Hospital, Thimphu, Bhutan
}

\begin{abstract}
Introduction: A three - year suicide prevention Action Plan was implemented in Bhutan from $1^{\text {st }}$ July 2015 to $30^{\text {th }}$ June 2018 to step up the fight against suicide in the country. Most of the strategies in the Action Plan had to be based on data from other countries due to lack of proper data on suicide within Bhutan. As a result, a National Suicide Registry (NSR) was established in January 2016. Health facilities were mandated to collect comprehensive information on every suicide case using the form developed by NSR. The purpose of the study was to generate information on characteristics of people who died by suicide by reviewing the cases from National Referral Hospital (NRH) for a period of two and half years. Methods: This was a record review of the suicide cases investigated by the hospital from $1^{\text {st }}$ January 2016 to $30^{\text {th }}$ June 2018. Descriptive statistics were used to analyze the data using Statistical Package for Social Sciences (SPSS) version 22 software. Results: Out of the total of 33 cases, $81.8 \%$ were below 40 years and $57.6 \%$ were female. Regarding education level, $30.3 \%$ did not have any education while $6.1 \%$ had Bachelor degree. In terms of employment, $45.5 \%$ were unemployed and $15.2 \%$ were students. Regarding income, $90.9 \%$ either did not earn or earned less than Nu. 1000 (USD 140.0) a month. With regards to health status, $81.8 \%$ did not have physical illness or disability while $45.5 \%$ had some form of psychiatric disorders and $60.6 \%$ of them experienced one or more forms of recent stressful life event prior to death by suicide. Conclusions: Majority of people who died by suicide were young and physically healthy adults from lower socio-economic status. Mental illness and stressful live events were other major characteristics among them.
\end{abstract}

Keywords: Mental illness; Stress; Suicide.

\section{INTRODUCTION}

Suicide is defined as the intentional killing of oneself by one's action. It is a complex human behavior with multiple psychological, social and cultural factors contributing to suicidal ideation and suicidal behavior ${ }^{1}$. Suicide is a serious public health issue globally ${ }^{2}$. As per World Health Organization (WHO), $79 \%$ of suicides in the world occur in low and middle-income countries $^{3}$. Suicide is one of the commonest causes of deaths among the young people living in developing countries ${ }^{4,5}$.

There are anecdotal evidences of rise in suicide cases in Bhutan. A survey conducted in 2013 found suicide as the sixth commonest cause of death in Bhutan. It also revealed the lack of a proper system to gather information regarding suicide in the country 6 .

\section{Corresponding author:}

Norbu

norbu@jdwnrh.gov.bt
In order to step up fight the against suicide in the country, the Royal Government of Bhutan formulated and implemented a three year Suicide Prevention Action Plan from 1 ${ }^{\text {st }}$ July 2015 to $30^{\text {th }}$ June $2018^{7}$. Many suicide prevention strategies and activities by different stakeholders were initiated under that Action Plan. However, due to lack of comprehensive national suicide data, most of the prevention strategies had to be based on regional and international data. In order to strengthen national data, evidence and information on suicide, a National Suicide Registry was established at the Ministry of Health under the Department of Public Health from 1 ${ }^{\text {st }}$ January 2016 as part of the Action Plan. As per the Manual of the Suicide Registry, all health facilities are mandated to report every suicide case to the Registry by submitting a duly filled National Suicide Case Reporting Form1 (CRF-1). The CRF-1 collects comprehensive demographic, socio-economic and health profiles as well as other information on each death by suicide.

The Forensic Medicine Department of the National Referral Hospital (NRH) is responsible for investigation of suicidal deaths from Thimphu district along with the Royal 
Bhutan Police. As mandated, the Department has started reporting suicide cases to the National Suicide Registry using CRF-1 from $1^{\text {st }}$ January 2016 . NRH is the largest reporting health facility in the country.

This study was undertaken to generate national information on characteristics of people who died by suicide based on the cases investigated by the Forensic Department, NRH from $1^{\text {st }}$ January 2016 to $30^{\text {th }}$ June 2018 using the data collected in the CRF-1. It is expected that the information generated from this study will be used for formulation of evidence based suicide prevention and response plans and policies in the country.

\section{METHODS}

After seeking approval from the Research Ethics Board of Health, Ministry of Health, Royal Government of Bhutan (Ref. No. REBH/Approval/2018/07, dated 01/10/2018), a descriptive record review was used to determine the characteristics of suicide cases that were investigated by NRH from $1^{\text {st }}$ January 2016 to $30^{\text {th }}$ June 2018.

All suicide cases investigated and recorded in the CRF1 were used as source of data for the study. Any case not recorded completely in the CRF-1 was excluded. CRF-1 captures detail information of every case.

There were thirty three cases that were investigated and recorded completely by the hospital during the above period. Each variable was collected from CRF-1 using a Data Collection Form. The variable included the age, sex, education level, employment status, average monthly income, marital status, known medical condition, known physical deformity or disability, known psychiatric condition, alcohol or drug use problem, any episode of deliberate self-harm in the past, any recent adverse life event, and method of suicide.

The data was analyzed using Statistical Package for Social Sciences (SPSS), version 22. The analysis was descriptive and quantitative. Frequency chart was used to analyze the variables.

\section{RESULTS}

As shown in Table 1, of 33 people who died by suicide, $21.2 \%$ were below 20 years of age, $60.6 \%$ (20) were between 20 to 39 years of age, and $18.2 \%$ were between 40 to 59 years of age. The youngest was 14 years of age and the eldest was 53 years of age. With regards to sex, $42.4 \%$ were male and $57.6 \%$ were female. With regards to education level, $30.3 \%{ }^{10}$ did not have formal education, $9.1 \%$ had only primary education (one to six years of schooling), 39.4\% had secondary education (seven to twelve years of schooling) while $6.1 \%$ of them completed tertiary level of education (Bachelors degree level and above) and 12.2\% of them were college students . With regards to marital status, $45.5 \%$ of them were married and $48.5 \%$ of them were unmarried.

As shown in Table 2, with regards to employment status, $27.3 \%$ were employed, $45.5 \%$ were unemployed while
Table 1. Demographic characteristics of suicide cases investigated by $\mathrm{NRH}^{*}$ from $1^{\text {st }}$ January 2016 to $30^{\text {th }}$ June $2018(n=33)$

\begin{tabular}{ll}
\hline Demographic characteristics & $\boldsymbol{n}(\mathbf{\%})$ \\
\hline Age in years (range: 14-53) & $7(21.2 \%)$ \\
Below 20 & $20(60.6 \%)$ \\
20 to 39 & $6(18.2 \%)$ \\
40 to 59 & \\
Sex & $14(42.4 \%)$ \\
Male & $19(57.6 \%)$ \\
Female & \\
Education level & $10(30.3 \%)$ \\
No formal education & $3(9.1 \%)$ \\
Primary education & $13(39.4 \%)$ \\
Secondary education & $6(18.2 \%)$ \\
Tertiary education & $1(3 \%)$ \\
Unknown & \\
Marital status & $15(45.5 \%)$ \\
Married & $16(48.5 \%)$ \\
Unmarried & $1(3 \%)$ \\
In relationship & $1(3 \%)$ \\
Status not known &
\end{tabular}

"National Referral Hospital

$15.2 \%$ were students. In terms of average monthly income, $90.9 \%$ were either not earning or earning less than $\mathrm{Nu} .10,000$, while only $6.1 \%$ were earning $\mathrm{Nu}$. 20,001 or more. With regards to life events, $60.60 \%$ of them had one or more recent stressful life events before death. Of those stressful life events, $15.2 \%$ had divoce or relationship breakup issues, $6.1 \%$ had lost family member or loved one, $6.1 \%$ had come into conflict with law. Rest of the people had stressful life events such as recent diagnosis of significant illness, recent episode of humilation or scolding, failing exam or interview, business misfortune etc. Of the remaining, $27.3 \%$ of them did not have any recent stressful life event and the status was not known in $12.1 \%$ of them.

As shown in Table 3,with regards to the health profile, $81.8 \%$ were free of any medical condition and $93.9 \%$ did not have any deformity or disability while $45.5 \%$ had some form of mental/psychiatric illness. Depression was found in $15.2 \%$ and $24.2 \%$ had alcohol/drug use problems.

With regards to past history of deliberate self- harm, $18.2 \%$ had such past history and $15.2 \%$ left one form of suicide note. Regarding the method of suicide, $72.7 \%$ chose hanging as method of suicide while $9.1 \%$ chose ingestion of drugs/poisons and $6.1 \%$ died by jumping into river as shown in Table 4. 
Table 2. Socio-economic characteristics of suicide cases investigated by NRH* from $1^{\text {st }}$ January 2016 to $30^{\text {th }}$ June $2018(n=33)$

\begin{tabular}{ll}
\hline Socio-economic characteristics & $\boldsymbol{n}(\%)$ \\
\hline Employment status & $15(45.5 \%)$ \\
Unemployed & $9(27.3 \%)$ \\
Employed & $4(12.1 \%)$ \\
Self employed (business) & $5(15.2 \%)$ \\
Students & \\
Average monthly income & $30(90.9 \%)$ \\
Nu: 00 to 10,000 & $1(3 \%)$ \\
Nu: 10,001 to 20,000 & $2(6.1 \%)$ \\
Nu: 20,001 and above & \\
Past history of intimate partner violence & $1(3 \%)$ \\
Yes & $32(97 \%)$ \\
No & \\
Past history of sexual assault & $1(3 \%)$ \\
Yes & $32(97 \%)$ \\
No & \\
Recent stressful life event & $20(60.6 \%)$ \\
Yes & $9(29.3 \%)$ \\
No & $4(12.1 \%)$ \\
\hline Unknown &
\end{tabular}

*National Referral Hospital

Table 3. Health profile characteristics of suicide cases investigated by NRH* from $1^{\text {st }}$ January 2016 to $30^{\text {th }}$ June $2018(n=33)$

\begin{tabular}{ll}
\hline Health profile characteristics & $\boldsymbol{n}(\boldsymbol{\%})$ \\
\hline Any known medical condition & \\
Yes & $5(15.2 \%)$ \\
No & $27(81.8 \%)$ \\
Unknown & $1(3 \%)$ \\
Any known deformity or disbility & \\
Yes & $0(0 \%)$ \\
No & $31(93.9 \%)$ \\
Unknown & $2(6.1 \%)$ \\
Any known psychiatric condition & \\
Yes & $15(45.5 \%)$ \\
No & $18(54.5 \%)$ \\
Unknown & $0(0 \%)$ \\
Alcohol or drug use disorder & \\
Yes & $8(24.2 \%)$ \\
No & $22(66.7 \%)$ \\
Unknown & $3(9.1 \%)$ \\
\hline
\end{tabular}

*National Referral Hospital
Table 4. Past history of deliberate self-harm, Suicide note and Method of suicide used in cases of suicide investigated by NRH* $^{*}$ from $1^{\text {st }}$ January 2016 to $30^{\text {th }}$ June $2018(n=33)$

\begin{tabular}{ll}
\hline Characteristics & $\boldsymbol{n}(\boldsymbol{\%})$ \\
\hline Past history of deliberate self harm & \\
Yes & $6(18.2 \%)$ \\
No & $27(78.8 \%)$ \\
Suicide note found & \\
Yes & $5(15.2 \%)$ \\
No & $28(84.8 \%)$ \\
Method of suicide & \\
Hanging & $24(72.7 \%)$ \\
Jumping into river & $2(6.1 \%)$ \\
Ingestion of drugs/poisons & $3(9.1 \%)$ \\
Others & $4(12.1 \%)$ \\
\hline
\end{tabular}

${ }^{*}$ National Referral Hospital

\section{DISCUSSION}

In this study, the major characteristics associated with suicide were young adult age, unemployment, low education level, low monthly income, mental illnesses, and stressful live events. The findings from this study are consistent with the findings on suicide from other underdeveloped and developing countries which also found those who died by suicide to be mostly healthy young adults from the more vulnerable and disadvantaged sections of society $^{8}$. The only notable difference was the higher number of women than men who died by suicide in this study. Globally, the age standardized suicide rate was 1.8 times higher in males than in females ${ }^{9}$.

Many people, including policy makers and health professionals assume mental illness as the underlying reasons for most of suicide cases and believe in strengthening mental health services as the main tool to combat suicide in the community. Studies also found psychiatric disorders as major risk factors for suicide ${ }^{10}$.

However, there are people who assume suicide as a socio-economic issue rather than pure mental problem ${ }^{10}$. They believe in improving socio-economic status of people as the main tool to combat suicide in the country. Studies of farmer suicides in India showed distress resulting from socio-economic hardships due to crop failures as the main risk factor for suicide among farmers ${ }^{12}$.

There is also strong association between mental illness and socio-economic hardship. It is a well known fact that mental illnesses like depression, anxiety disorders, substance use disorders etc. can present as surface manifestations of underlying socio-economic stressors like unemployment, poverty, financial crisis, conflict with law, loss of loved ones, failure in exam/ 
interview etc ${ }^{13}$. At the same time, people with mental illnesses are at higher risk of socio-economic hardships by way of loss of jobs, irrational decision-makings, poor coping abilities etc.

In addition, there is a saying, "suicide is a permanent solution for a temporary problem". There seems to be some truth in this saying as, even in this study, more than sixty percent of them experienced some stressful life events before dying by suicide. It is likely that some of them took their lives to escape from the stressful life events. Positive coping skills and good psycho-social supports would have prevented some or most of these deaths.

Therefore, it is essential to appreciate the complex relationship between suicidal tendency, socio-economic hardships, mental illnesses, and stressful live events and address each of them holistically and comprehensively. A recent study on attempted suicide patients admitted to NRH from 2014 to 2018 also found socio-economic hardships, mental illnesses and stressful live events to be common characteristics among them ${ }^{14}$. Improving the socio-economic condition of general population, inculcation of emotional skills and social skills through education and community based systems and establishing easily accessible mental health and social support services will probably contribute in preventing sucidal thoughts and suicidal behaviours.

In this study, only $18.2 \%$ had history of deliberate selfharm or suicidal ideation. This rate is lower than findings from other studies. However it was likely to be underestimated as the relatives who provided the information either did not know of the incident or did not wish to provide true information. Previous history of attempted suicide or suicidal ideation is considered a major risk factor for suicide ${ }^{15}$. An international review of psychological autopsy studies found that about $40 \%$ of those who died by suicide had histories of attempted suicide ${ }^{16}$. Therefore, it is essential that people who present with deliberate self-harm and suicidal ideation are comprehensively assessed and assisted with necessary medical care and psycho-social supports to prevent further harms.

\section{LIMITATIONS}

The findings from this study may not reflect the situation of the entire country as the study reviewed the records available at NRH. The other limitation is that the information gathered in CRF1 were provided mostly by the family members and therefore, might not reflect the true details of the deceased.

\section{CONCLUSIONS}

Majority of people who died by suicide were young and physically healthy adults from lower socio-economic status. Mental illness and stressful life events were other major characteristics among them. Therefore, it is likely that improving the psychological well being, social support services and economic conditions of general population would reduce suicide in the country.

\section{RECOMMENDATIONS}

As this study showed that most of the suicide cases were associated with socio-economic hardships, stressful life events and mental illnesses, it is likely that interventions that could improve socioeconomic situations could help in decreasing the suicide rates in the country. Inculcating emotional and social skills among general population through education, training and communitybased systems might help in prevention of suicide. Establishing easily available and accessible mental health and social support services would also help in combating suicide ideations and actual commitment of suicide. However, further studies are recommended to generate more information on how each of the characteristics contributes to suicidal thoughts and behaviours. It is also important to undertake studies to find out why most of the people who died by suicide were physically healthy young adults. In addition, further studies are recommended to verify whether suicide rates for females are truly higher than for males in the country as found in this study. If it is confirmed, then it would be really necessary to undertake further studies, especially from gender equity perspective.

\section{REFERENCES}

1. Phillips MR, Yang GH, Zhang YP, Wang L, Ji H, Zhou M. Risk factors for suicide in China: a national case-control psychological autopsy study. Lancet. 2002;360:1728-1736. [Full Text | DOI]

2. O'Connor RC, Nock MK. The psychology of suicidal behaviour. Lancet Psychiatry. 2014;1(1):73-85. [PubMed | Full Text | DOI]

3. Suicide in the world: Global Health Estimates. Geneva: World Health Organization. 2019. [Full Text $\mid$ DOI]

4. Yip PS. Towards evidence based suicide prevention programs. Crisis: The Journal of crisis intervention and suicide prevention. 2011;32(3):117-120. [Full Text | DOI]

5. Krug EG, Dahlberg LL, Mercy JA, Zwi AB, Lozano R. World report on violence and health. Geneva: World Health Organization; 2002. 187p. [Full Text]

6. Lhadon K. Suicide trends in Bhutan from 2009 to 2013; Journal of Bhutan Studies. 2014;30:30-56.[Full Text]

7. Royal Government of Bhutan: Suicide Prevention in Bhutan-A Three Year Action Plan (2015-2018). Thimphu, Bhutan; 2015.[Full Text]

8. Lakshmi VK. Suicide Prevention: The urgent need in developing countries; World Psychiatry.2004;3:158-59. [Full Text] 
9. Varnik P. Suicide in the World. Int J Environ Res Public Health. 2012;9(3):760-771. [Full Text | DOI]

10. Wray M, Colen C, Pescosolido B. The Sociology of Suicide. Annual Review of Sociology.2011;37:1505-28. [Full Text]

11. Stucker D, Basu S, Suhrcke M, Coutts A, McKee M. Effects of the 2008 recession on health: a first look at European data. Lancet.2011; 378:125-135.[PubMed | DOI]

12. Merriott D. Factors associated with the farmers' suicide in India. Journal of Epidemiology and Global Health. 2016;6(4):217-227. [Full Text | DOI]

13. Molarius A, Berglund K, Erriksson C, Eriksson HG, LindénBoström M, Nordström E, et al. Mental health symptoms in relationship to socio-economic conditions and lifestyle factors: a population based study in Sweden. BMC Public Health. 2009;9:302. [Full Text | DOI]
14. Lethro Z, Wangmo N, Kuenzang K. Characteristics of Attempted Suicide Patients Admitted in Jigme Dorji Wangchuk National Referral Hospital from January 2014 to September 2018. Bhutan Health Journal.2021; 7(1):1-4.[Full Text | DOI]

15. Klonsky ED, May AM, Saffer BY. Suicide, suicide attempts, and suicidal ideation. Annu Rev Clin Psychol.2016;12:307-330. [Full Text]

16. Cavanagh J, Carson A, Sharpe M, Lawrie SM. Psychological autopsy studies of suicide: a systematic review. Psychological Medicine. 2003;33:395-405. [PubMed | Full Text | DOI]

\section{AUTHORS CONTRIBUTION}

Following authors have made substantial contributions to the manuscript as under:

N: Concept, design, data collection and analysis, manuscript writing and review.

CD: Concept, design, data collection and analysis, manuscript writing and review

KN: Concept, design, data collection and analysis, manuscript writing and review

KP: Concept, design, data collection and analysis, manuscript writing and review

Author agree to be accountable for all respects of the work in ensuring that questions related to the accuracy and integrity of any part of the work are appropriately investigated and resolved.

CONFLICT OF INTEREST

None

GRANT SUPPORT AND FINANCIAL DISCLOSURE

None 